\title{
XLIII. The mental multiplication and division of large numbers
}

\section{V.A. Bailey M.A.}

To cite this article: V.A. Bailey M.A. (1921) XLIII. The mental multiplication and division of large numbers, Philosophical Magazine Series 6, 42:249, 390-397, DOI: 10.1080/14786442108633774

To link to this article: http://dx.doi.org/10.1080/14786442108633774

曲 Published online: 08 Apr 2009.

Submit your article to this journal

Џll Article views: 5

Q View related articles $\square$

Citing articles: 2 View citing articles 5 
rational coefficients. The most natural ways of wellordering these are such that those of low order and degree, and involving no numerical constants other than small integers and fractions with small numerators and denominators, come earliest in the sequence. Accordingly, the practice of adopting the simplest law that fits the available observations appears to be closely related to the possibility of a satisfactory theory of inference.

XLIII. The Mental Multiplication and Division of Large Numbers. By V. A. Baller, M.A., Queen's College, Oxford *

TTHE current methods of long multiplication and division have been in existence practically since the twelfth century, when they were given by the Hindoo Mathematician Bhaskara.

Some of the modifications of these methods are given in the Encyclopedia Brittanica, 11th edition, Article "Arithmetic." In particular, mention is made of a process of long multiplication which may be performed wholly mentally, though with some difficulty.

The process described below may be regarded as a development and simplification of this last, though originally arrived at independently.

After very little practice with this new method the author has found it to possess the following other advantages over the ordinary method :-

(1) It is speedier.

(2) Less liable to error.

(3) Less fatiguing for large numbers.

(4) By reversing the process we can perform long division mentally.

The method is best explained by indicating the steps in an actual example.

Let us evaluate $24968 \times 4352$.

On a slip of paper write down the multiplier backwards, taking care to give the figures the same spacing as the multiplicand. Start with the left-hand digit on the slip placed under the right-hand digit of the multiplicand thus :-

24968

2534 .

* Communicated by the Author. 
Then multiply together the two digits in the same vertical column :-2 $2 \times 8=16$.

Write down 6 as the unit digit in the answer, and mentally "carry 1 " to the next stage.

For the second stage move the slip one digit to the left, thus :-

$$
24968.2 .
$$

Add the products of the pair of digits in the same vertical column and the " 1 carried over" :-

$$
\text { " } 1 \text { carried over" }+5 \times 8+2 \times 6=53 \text {. }
$$

Write down 3 as the tens digit in the answer and "carry 5 " to the next stage.

\begin{tabular}{|c|c|c|c|c|}
\hline Stage. & Position of Slip. & Mental Process. & $\begin{array}{l}\text { Jarry } \\
\text { over. }\end{array}$ & $\begin{array}{l}\text { State of the } \\
\text { answer. }\end{array}$ \\
\hline 3. & $\begin{array}{r}24968 \\
2534\end{array}$ & $\begin{array}{c}5+3 \times 8+5 \times 6+2 \times 9 \\
=77\end{array}$ & 7 & $\ldots \ldots 736$ \\
\hline 4. & $\frac{24968}{2534}$ & $\begin{array}{c}7+4 \times 8+3 \times 6+5 \times 9 \\
+2 \times 4=110\end{array}$ & 11 & $\ldots 0736$ \\
\hline 5. & $\frac{24968}{2534}$ & $\begin{array}{c}11+4 \times 6+3 \times 9+5 \times 4 \\
+2 \times 2=86\end{array}$ & $s$ & $\ldots 60736$ \\
\hline 6. & $\frac{24968}{2534}$ & $\begin{array}{c}8+4 \times 9+3 \times 4+5 \times 2 \\
=66\end{array}$ & 6 & $\ldots 660736$ \\
\hline 7. & $\frac{24968}{2534}$ & $\begin{array}{c}6+4 \times 4+3 \times 2 \\
=28\end{array}$ & 2 & .8660736 \\
\hline 8. & $\frac{24968}{2534}$ & ${ }^{2+4 \times 2}=10$ & - & 108660736 \\
\hline
\end{tabular}

The rest of the calculation is shown in the following table :-

Thus the answer is 108660736 .

A step by step comparison of this process with the ordinary method of multiplication will soon suffice to convince anyone of its correctness. 
392 Mr. V. A. Bailey on the Mental Multiplication

Alter practising this method half-a-dozen times with numbers similar to those given in the example one becomes capable of dealing easily with products like

$$
2490731 \times 7615429 \text {. }
$$

It is not very difficult after a little practice to add up mentally a series like $27+56+49+18$, and in time one can do it as easily as one normally does the series

$$
3+7+9+4+8+5 \text { say. }
$$

As an instance where the method has an exceptional advantage over ordinary multiplication we can take the product $2307103405 \times 60802040105$.

In less than two minutes we find mentally that the answer is 140276593757192057525 .

It takes decidedly longer to do by the ordinary process. Of course in a general case the difference will not be as great.

Suppose it is required to evaluate a product only as far as the first $n$ significant figures. The rule for this is : start the process with the right-hand digit on the slip under the $(n+1)$ th digit from the left of the multiplicand. For example, to get $24968 \times 4352$ as far as the first 5 significant figures we start thus:- $\quad 24968$

$$
2534 \text {. }
$$

This gives 108660200 , in which we can be sure only of the first five figures.

The transition from accurate to approximate and abbreviated multiplication is done quite naturally by this method and involves learning only one rule.

The use of an ordinary 12 -inch slide-rule is equivalent to the determination of the first 3 significant figures in products of numbers like 5:34 and 869 .

If we would proceed for $534 \times 869$ by starting at 534 we arrive at an answer 463500 while the exact result is 464046. This is as near as we can get on a slide-rule, so in the absence of such an instrument the method just cited is a gond substitute.

The reversed process, which enables one to perform mental long division, is not so easily carried out, but with some practice the method is not much more troublesome than ordinary long division.

The difficulties that arise are exactly the same as those that arise for anyone learning ordinary long division for the 
first time. These difficulties disappear in the mental method with practice, as they do in the other.

Let us take as an example $7102983 \div 578$. This time we use the slip of paper to write the answer on, backwards, as will be seen.

Start with the right end of the blank slip under the 5 in 578 , thus :

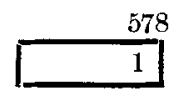

and under the 5 write the obvious first figure in the answer, namely 1 . Then subtract $1 \times 5$ from the 7 in the dividend leaving 2 , which together with the 1 in the dividend forms 21 for the next stage.

Now move the slip one nigure to the right, thus :

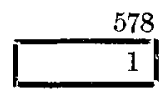

The process is $21-1 \times 7=14 ; \frac{14}{5}=2$ and 4 over.

Write down 2 on the slip under the 5 , while the 4 together with the 0 in the dividend forms 40 for the next stage.

Ag:tin move the slip one figure, thus :-

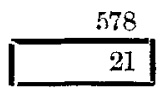

and perform the process $40-1 \times 8-2 \times 7=18 ; \frac{18}{5}=3$ and 3 over.

On trial, however, it will be found that the 3 is too high, so we will take $\frac{18}{5}=2$ and 8 over.

Write down 2 on the slip under the 5 , while the 8 together with the 2 in the dividend forms 82 for the next stage.

The next position of the slip is

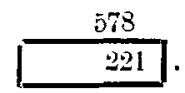

Perform the process $82-2 \times 8-2 \times 7=52 ; \frac{52}{5}=9$ and 7 over (since 10 is inadmissible as a digit).

For the next stage we have 79 and the position

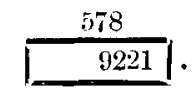


The usual process gives $79-2 \times 8-9 \times 7=0$, so that at the following stage our process gives us $8-72=-64$, which plainly is inadmissible on account of its negative sign. Hence we must return to the stage just two before the last where we put $\frac{52}{5}=9$ and 7 over, and instead we try $\frac{52}{5}=8$ and 12 over.

Thus the next slip position is

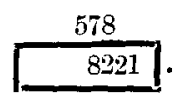

The process is $129-2 \times 8-8 \times 7=57 ; \frac{57}{5}=8$ and 17 over (as 9 and 12 over is abandoned on trial).

We have now found the integral part of the answer to be 12288, written on the slip as 88221. If it is desired to obtain the fractional part in decimal form, it is only necessary to continue the above process, adding zeroes to the dividend as wanted.

But if the "remainder" is required then one proceeds as follows :-carrying on from the last stage we have as a new slip position

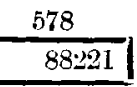

and the usual process is $178-8 \times 8-8 \times 7=58$; then put $\frac{58}{5}=0$ and 58 over *.

The next stage is

578

088221

and $583-8 \times 8-0 \times 7=519$.

As soon as all the figures in the dividend are used up we stop, and the final figure 519 is the required remainder.

This process for getting the remainder is seen to be justifiable, if we begin the mental multiplication of 578 by 12288 and add 519 simultaneously.

As it is not easy to explain the metbod of mental division fully with one example, another is given in tabular form (p.395).

In learning these mental methods it may be advisable at first to perform part of the calculation on paper, or to write down the "carry over." But it is astonishing how soon one can drop these crutches.

* At each stage put $\frac{N}{5}=0$ and $N$ over, but otherwise proceed as usual. 
and Division of Large Numbers.

To evaluate $16302581 \div 478$.

\begin{tabular}{|c|c|c|c|c|}
\hline Stage. & Position of Slip. & Mental Process. & $\begin{array}{c}\text { For } \\
\text { next } \\
\text { Stage. }\end{array}$ & Remarks. \\
\hline 1. & 478 & $\frac{16}{4}=3 \& 4$ over & 43 & \\
\hline 2. & $\frac{478}{3}$ & $\begin{array}{l}43-3 \times 7=22 \\
\frac{22}{4}=4 \& 6 \text { over }\end{array}$ & 60 & \\
\hline 3. & $\frac{478}{43}$ & $\begin{array}{c}60-3 \times 8-4 \times 7=8 \\
\frac{8}{4}=1 \& 4 \text { over }\end{array}$ & 42 & \\
\hline 4. & $\frac{478}{143}$ & $\begin{array}{c}42-4 \times 8-1 \times 7=3 \\
\frac{3}{4}=0 \& 3 \text { over }\end{array}$ & 35 & \\
\hline 5. & $\frac{478}{0143}$ & $\begin{array}{c}35-1 \times 8-0 \times 7=27 \\
\frac{2 \pi}{4}=5 \& 7 \text { over }\end{array}$ & 78 & $\begin{array}{l}\text { Hence integral part } \\
\text { of the quotient is } \\
3410 \overline{5} \text {. }\end{array}$ \\
\hline $6 a$. & $\frac{478}{50143}$ & $\begin{array}{c}78-0 \times 8-5 \times 7=43 \\
\frac{43}{4}=8 \& 11 \text { over }\end{array}$ & 111 & $\begin{array}{l}\text { Procedure to get } 3 \\
\text { decimal places given } \\
\text { in } 6 \alpha, 7 a, 8 a \text {. }\end{array}$ \\
\hline $7 a$. & $\frac{478}{850143}$ & $\begin{array}{c}111-5 \times 8-8 \times 7=15 \\
\frac{15}{4}=1 \& 11 \text { over }\end{array}$ & 110 & \\
\hline $8 a$. & $\frac{478}{1850143}$ & $\begin{array}{c}110-8 \times 8-1 \times 7=39 \\
\frac{39}{4}=8 \& 7 \text { over }\end{array}$ & 70 & $\begin{array}{l}\text { The quotient to } 3 \\
\text { decimal places is } \\
34105.818 \text {. }\end{array}$ \\
\hline $6 b$. & Same as $6 a$. & $\begin{array}{c}78-0 \times 8-5 \times 7=43 \\
\frac{43}{4}=0 \& 43 \text { over }\end{array}$ & 43 & $\begin{array}{l}\text { Procedure to get the } \\
\text { "Remainder" given } \\
\text { in } 6 b, 7 b \text {. }\end{array}$ \\
\hline $7 b$. & $\frac{478}{0501043}$ & $431-5 \times 8=391$ & - & $\begin{array}{l}\text { Hence "Remainder" } \\
\text { is } 391 .\end{array}$ \\
\hline
\end{tabular}

If the multiplication happens to be a squaring problem, we can if we choose avoid the use of a slip in the following way :-let us square 12083 ; cover the 1208 with one's hand and proceed with $3^{2}=9$. 


\section{Mental Multiplication and Division of Large Numbers.}

Then 9 is unit digit of answer and "carry zero."

Uncover 8 and proceed with " $0 "+(8 \times 3) \times 2=48$.

Then 8 is tens digit, and "carry 4. "

Uncover 0 and proceed with " 4 " $+(0 \times 3) \times 2+8^{2}=68$.

Then 8 is hundreds ligit and " carry $6 . "$

Uncover 2 and proceed with " $6 "+(2 \times 3+0 \times 8) \times 2=18$, and so on. When we have uncovered the whole of the number, we next begin covering up the digits, beginning from the right end.

By reversing the above process in a manner analogous to mental division we can obtain square roots to any degree of accuracy desired.

Suppose we require $\sqrt{12 \cdot 1}$. The first figure is plainly 3 . Work out $12-3^{2}=3$. To the 3 tack on the next integer in the square, viz. 1, making 31 . Then $\frac{31}{6}=4$ and 7 over, the 6 being $2 \times$ (1.st digit in the root), which will be our only divisor throughout the calculation. To the 7 rack on the next digit in the square, viz. 0 , and proceed as follows (line alter line), the corresponding stage of the answer (minus its first digit) being shown on the extreme right :-

$$
\begin{array}{r|l|l}
70-4^{2}=54 & \frac{31}{6}=4 \& 7 \text { over } & \cdot 4 \\
120-2(4 \times 7)=64 & \frac{54}{6}=7 \& 12 \text { over } & \cdot 47 \\
160-2(4 \times 8)-7^{2}=47 & \frac{64}{6}=8 \& 16 \text { over } & \cdot 478 \\
170-2(4 \times 5)-2(7 \times 8)=18 & \frac{47}{6}=0 \& 17 \text { over } & \cdot 4785 \\
180-2(4 \times 0)-2(7 \times 5)-8^{2}=46 & \frac{16}{6}=5 \& 16 \text { over } & \cdot 47850 \\
160-2(4 \times 5)-2(7 \times 0)-2(8 \times 5)=40 & 40=4816 \text { over } & \cdot 478505 \\
& 4785054
\end{array}
$$

Of course we have here left ont trials like $\frac{64}{6}=9$ and 10 over or $\frac{18}{6}=1$ and 12 over, which would have given us negative remainders on the left. Hence

$$
\sqrt{12 \cdot 1}=3 \cdot 4785054 \text {. }
$$

This is easily verified to be correct, for

$$
\sqrt{12 \cdot 1}=1 \cdot 1 \sqrt{10}=1 \cdot 1(3 \cdot 1622776602) .
$$


The methods of mental division and mental determination of square roots are given here only for the sake of interest. The author does not intend to recommend them for practical use until he has had sufficient experience of their merits or otherwise.

But the method of mental multiplication has serious claims to our attention (already mentioned), and rery little experience with it makes one feel that if one had been brought up on it from childhood in place of the ordinary method, then the multiplication of large numbers would have its terrors considerably lessened.

XLIV. The Effect of Temperature on the Modulus of Rigidity, and on the Viscosity of Solid Metals. By $\mathrm{K}_{\mathrm{EX}}$ IoKrB⿷ and Sukeaki Sakai *.

\section{Introduction.}

TVHE effect of temperature on the modnulus of rigidity of different metals has heen a favourite subject of many investigators. In most of the previous investigations the range of temperature was very limited, not much exceeding $300^{\circ} \mathrm{C}$. Kohlrausch \& Loomis + , Pisati $\ddagger$, and Tomlinson $\S$ investigated the effect of temperature on rigidity below $300^{\circ}(1$. , and proposed the formula of the form

$$
n_{t}=n_{0}\left(1-\alpha t-\beta t^{2}\right) \text {, }
$$

where $u_{t}$ and $n_{0}$ are the values of rigidity at $t^{\circ}$ and $0^{\circ}$ respectively. Experiments have also been made by Katzenelsolin \#, Gray, Blyth \& Dunlop I, and Sutherland **, the latter confining his researches to the softer metals, such as lead, zinc, tin, and magnesium, which had been neglected by former investigators. He also obtained a formula of the type

$$
\overline{\mathrm{N}}=1-\left(\frac{\mathrm{T}}{\mathrm{T}_{0}}\right)^{2},
$$

where $\mathrm{N}$ is the value of rigidity at absolute zero, and $\mathrm{T}_{0}$ the melting-point in absolute scale.

* Conmunicated by the Authors.

† Prgg. Ann. vol. cxli. p. 481 (1870).

I Nuovo Cimento, ser. 3 , vol. i. p. 181 ; ii. p. 137 ; 1v. p. 152 ; r. pp. 34, $13 \tilde{a}-1 \pm 5(1877-79)$.

Proc. Roy. Sor. vol. xl. p. 313 (1886).

il Beibl. vol. xii. p. 307 (1888).

Tी Proc. Roy. Soc. vol. lxvii. p. 180 (1900).

** Phil. Mag. (5) vol. xxxii. p. 31 (1891). 